\title{
Research on the Optimization of C Company's After-sale Service Quality Based on
}

\section{Six Sigma}

\author{
Xiaozhe Li, Qingqing Lu, Yijun Li \\ Management Engineering College, Zhengzhou University, Zhengzhou, China \\ 136753803@qq.com,957478616@qq.com,118134415042@163.com
}

Keywords: After-sales service quality, Six Sigma, DMAIC process

\begin{abstract}
In order to improve after-sales service quality better, this paper takes $C$ company as an example, using the DMAIC process of Six Sigma to analyze the related factors to after-sales service quality. Through the use of fishbone diagram, arrangement chart, quality function deployment, FEMA analysis and other methods, the paper confirms the influencing factors of service quality and the direction to be improved. According to the result of the analysis, it is determined to improve the after-sales service management system and after-sales service flow used in the enterprise, and the improved validity is verified through the analysis of the improved after-sales processing time.
\end{abstract}

\section{INTRODUCTION}

The quality of after-sales service is playing an increasingly important role in consumers' shopping. While ensuring the quality of its products, the improvement of after-sales service will enable enterprise to retain more customers. Based on the introduction of the basic situation of $\mathrm{C}$ company, this paper studies the quality of after-sales service of C company in combination with the relevant methods of Six Sigma. Finally, according to the problems of the C company, we propose an optimized scheme to improve the quality of the final service of $\mathrm{C}$ company and verify the effectiveness of the improved scheme.

Li Chunyan (Chunyan Li, 2005) illustrated the concept of "customer-centric, surpass customer expectation" of Six Sigma through the example of Motorola, elaborated the customer to customer expectations as the starting point, in the whole life cycle of products in the understanding of customer needs and customer satisfaction. Shing-Han Li and others (Li S H, Wu C C, 2011) made use of DMAIC to improve the helpdesk service system to help companies improve service quality and efficiency. Dong Changming and Gao Qisheng (Changming Dong, QiSheng Gao, 2014) used the DMAIC process in Six Sigma to analysis the service of commercial banks and got the major improvement in commercial banks' impact on customer satisfaction. Yin Xueyang (Xueyang Yin,2010) carried out the application of the DMAIC process to the automobile after-sales service, and found out the key factors through the CSI as the main direction for after-sales service improvement so as to improve customer satisfaction. The continuous application of Six Sigma theory in the service industry shows the effectiveness of this method in improving customer satisfaction. The DMAIC process in Six Sigma is an effective way to improve the service quality.

\section{THE DEFINING STAGE OF C COMPANY}

The defining phase of C company is the initial stage of Six Sigma and the starting point for project and problem identification.

\subsection{After-sales Service Description and Status Quo Analysis}

To understand the basic situation of C company service is the beginning to solve the problem. The after-sale procedures of the company's current products are as follows: (1) the contact information of the market quality of information; (2) acceptance of quality information management / processing; (3) quality information processing time; (4) the investigation; (5) reply.

\subsection{Analysis of the Causes of After-sales Service Problems}

The company's marketing department was investigated by brainstorming. The relevant literature was summarized to obtain relevant data. Through the collation of the data, the final brainstorming method to reflect the problem summarized, using fishbone diagram to reflect, the final results are summarized as follows. The main source of fishbone ultimately reflect the influence of customer dissatisfaction which is five aspects of personnel, environment, product, process, machine. They can be specified as poor professional ability, poor service attitude, communication barriers, service process is time-consuming, complex process, difficult to control the production process, there is no such good environment, product contract the product is too complex, lack of attraction, lack of machine and fault.

\section{MEASUREMENT STAGE OF C COMPANY}

The measurement phase is the continuation of the previous stage.It is a certain observation and consideration of the target that has been determined. The continuous mining of data drives the exposure of defects, so as to improve the defects (Sushovan, Ghosh., J, Maiti., 2014). 


\subsection{Data Collection and Statistics}

This paper collects and counts the data collected by $\mathrm{C}$ company's after sales customer feedback system. Because customers reflect the problems involved in all aspects, according to the statistical analysis of the results of customer demand, it can be reflected in the customer is divided into three categories. Three types are: (1) the problem of after-sales service; (2) the contract; (3) quality problems. The three types of problems are counted and the three specific problems with the highest proportion are obtained. The statistics are shown in Table 1 below:

Table 1: After sales service statistics.

\begin{tabular}{|c|c|c|}
\hline Type & Project & Proportion \\
\hline \multirow{4}{*}{$\begin{array}{c}\text { The problem of } \\
\text { after-sales } \\
\text { service }\end{array}$} & $\begin{array}{c}\text { Delay delivery } \\
\text { time }\end{array}$ & $31.93 \%$ \\
\cline { 2 - 3 } & $\begin{array}{c}\text { The timeliness } \\
\text { of after-sales } \\
\text { service is slow }\end{array}$ & $25.16 \%$ \\
\cline { 2 - 3 } & $\begin{array}{c}\text { Do not fulfill } \\
\text { sales } \\
\text { commitment }\end{array}$ & $5.23 \%$ \\
\hline \multirow{4}{*}{ The contract } & Unequal terms & $8.72 \%$ \\
\cline { 2 - 3 } & Contract breach & $5.31 \%$ \\
\cline { 2 - 3 } Quality & $\begin{array}{c}\text { Contracting } \\
\text { negligence }\end{array}$ & $1.02 \%$ \\
\hline \multirow{4}{*}{ problems } & $\begin{array}{c}\text { Product } \\
\text { performance } \\
\text { issues }\end{array}$ & $36.88 \%$ \\
\cline { 2 - 3 } & $\begin{array}{c}\text { Unqualified } \\
\text { product }\end{array}$ & $8.54 \%$ \\
\cline { 2 - 3 } & $\begin{array}{c}\text { Failure and } \\
\text { damage }\end{array}$ & $6.20 \%$ \\
\hline
\end{tabular}

\subsection{Data Analysis}

According to the statistical problems, it can be found that each of them has an important impact on customer satisfaction and each problem will cause strong customer dissatisfaction. Therefore, according to the formula: the proportion of each item / total proportion, the proportion of all items in each item is obtained.

Table 2: Problem sequencing.

\begin{tabular}{|c|c|c|c|}
\hline Project & Proportion & $\begin{array}{c}\text { the } \\
\text { proportion } \\
\text { of each item } \\
\text { / total } \\
\text { proportion }\end{array}$ & $\begin{array}{c}\text { Cumulative } \\
\text { proportion }\end{array}$ \\
\hline $\begin{array}{c}\text { A: Product } \\
\text { performance issues }\end{array}$ & $36.88 \%$ & $28.59 \%$ & $28.59 \%$ \\
\hline $\begin{array}{c}\text { B: Delay delivery } \\
\text { time }\end{array}$ & $31.93 \%$ & $24.75 \%$ & $53.34 \%$ \\
\hline $\begin{array}{c}\text { C: } \text { The timeliness } \\
\text { of after-sales } \\
\text { service is slow }\end{array}$ & $25.16 \%$ & $19.51 \%$ & $72.85 \%$ \\
\hline D: Unequal terms & $8.72 \%$ & $6.76 \%$ & $79.61 \%$ \\
\hline $\begin{array}{c}\text { E: Unqualified } \\
\text { product }\end{array}$ & $8.54 \%$ & $6.62 \%$ & $86.23 \%$ \\
\hline $\begin{array}{c}\text { F: Failure and } \\
\text { damage }\end{array}$ & $6.20 \%$ & $4.81 \%$ & $91.04 \%$ \\
\hline $\begin{array}{c}\text { G: Contract } \\
\text { breach }\end{array}$ & $5.31 \%$ & $4.12 \%$ & $95.16 \%$ \\
\hline $\begin{array}{c}\text { H: Do not fulfill } \\
\text { sales commitment }\end{array}$ & $5.23 \%$ & $4.05 \%$ & $99.21 \%$ \\
\hline $\begin{array}{c}\text { I: Contracting } \\
\text { negligence }\end{array}$ & $1.02 \%$ & $0.79 \%$ & $100 \%$ \\
\hline
\end{tabular}

After processing the data of each project, the data is sorted, and the ordering rules are sorted from large to small according to the proportion. The table 2 is obtained.

The key problems are determined by the arrangement diagram analysis of the problems and proportions reflected in Table 2. The specific results are shown in Figure 1 below.

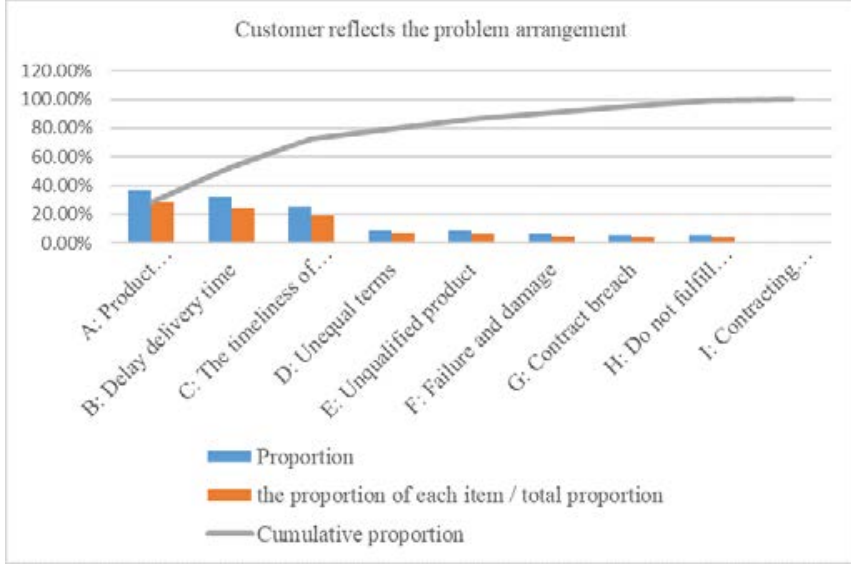

Figure 1: Analysis of Customer Problems Arrangement Chart.

As can be seen from Figure 1, the total proportion of projects $\mathrm{A}, \mathrm{B}, \mathrm{C}$, and $\mathrm{D}$ is about $80 \%$, which shows that the key to the problem lies in product performance problems, delay in delivery time, slow aging service, inequality Terms of the four aspects, so the four aspects identified as the key elements cause customer dissatisfaction.

\section{C COMPANY'S ANALYSIS STAGE}

The analysis phase is the most important part of the company's implementation of the Six Sigma, whose purpose is to identify the root of the problem. In order to achieve this goal, it is necessary to further analysis and explore the data collected in the measurement phase. We can find the deeper relationship between variables and provide specific direction for the next step of improvement.

\subsection{The Quality of Service Quality Features to Start}

This article uses QFD to define the key elements of the arrangement. The quality function to expand the left wall is the customer's requirement. The ceiling is the $\mathrm{C}$ company-related service requirement. The room is a matrix of related coefficients that determine the correlation between the left-wall project and the ceiling project, the roof on behalf of the project's relationship, Basement on behalf of the various technologies, capabilities, the total importance of after-sales projects.

The determination of the correlation matrix in the room is done by a questionnaire survey of the marketing department staff and finally the mean value of the questionnaire is filled in. The roof indicates the correlation between the after-sales service requirements, including: positive correlation, negative correlation, Relationship, under normal circumstances with $\circ$ that the 
positive correlation, with $\times$ that negative correlation, were marked on the roof of the corresponding location.

According to Figure 2, the importance of the quality of service requirements is different, in which the problem of processing time is the most important of these projects. According to the expansion of the house of quality, the paper further analysis the processing time of after sale service and finds out the key aspects affecting the after-sale service processing time, and improves it after analysis.

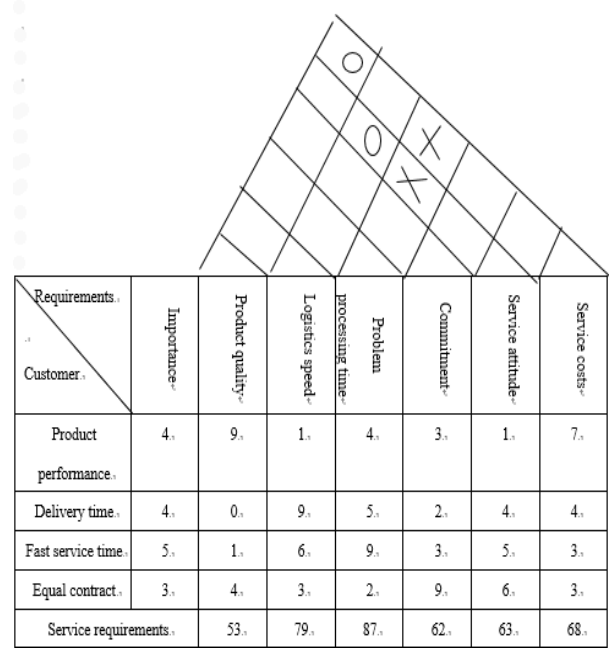

Figure 2: Quality function analysis chart.

\subsection{Analysis of Key Quality Characteristics}

Analysis of the characteristics of recognition of $\mathrm{C}$ company's quality of service selection tool for FEMA. FEMA analysis starts from the selected process, and continuously analyzes the contents of the process. It finally finds the cause of the problem, and determines the specific improvement aspects through the evaluation of the reasons. We determine the relevant improvement measures in determining the direction of improvement after.

From the quality function deployment, it can be seen that the key to the change is the processing time of the problem. The process name and function in the analysis are determined as the processing time of the problem. According to the severity of the potential failure mode affecting the customer, it is considered that the slow aging of after-sales service will affect the process of after-sales service, so the severity is 8 .

Through the analysis of after-sales service process to determine the existence of after-sales service may cause service problems to solve the problem of aging slowly for three reasons, that is, after-sales service staff too little service personnel service level is not high service The process is more complicated and is reflected in the FEMA analysis table.

According to frequency evaluation table and detection evaluation table, we determine the frequency of each cause and detection, and fill in the FEMA analysis of the relevant position.

Finally, according to RPN $=\mathrm{S} * \mathrm{O} * \mathrm{D}$, we calculate and determine the risk of each reason. By comparing the degree of risk, we get the last key reason. Finally, the results are summarized in the FEMA analysis table in Figure 3 to get the key improvements.
According to the result of FEMA analysis, it can be seen that the complicated service process is the key issue affecting the after-sales service processing time. To improve the after-sales service aging and meet the customer's requirements, the after-sales process needs to be improved.

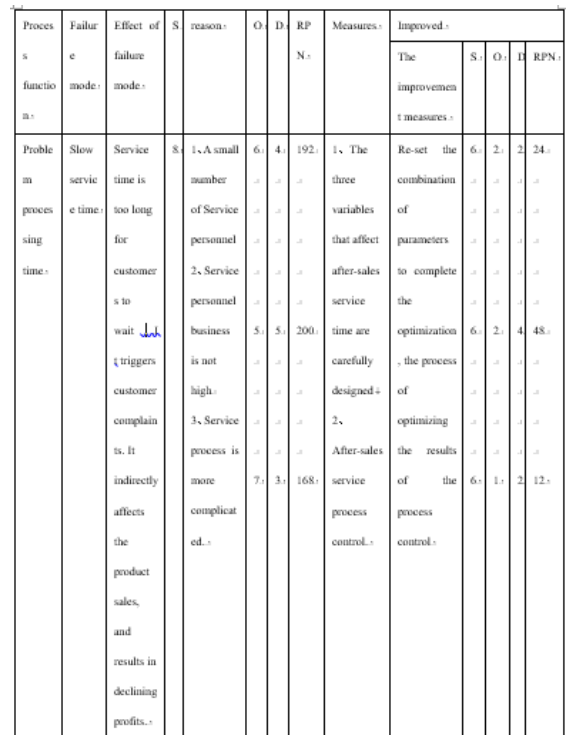

Figure 3: FEMA analysis.

\section{THE IMPROVEMENT STAGE OF C COMPANY}

The improvement phase of C company is a crucial stage in the implementation of Six Sigma. At this stage, we need to make an in-depth analysis of the identified root causes and put forward relevant improvements. The purpose of improvement is to enable enterprises to get the maximum satisfaction of customers with minimum effort, so as to retain users or buyers.

Putting forward the optimization plan

As can be seen from the FEMA analysis table, the service process has a greater impact on the processing time of the problem. There are two controllable impact factors in service processes, namely systems and processes for processing. Processing system is the company's hardware equipment, improvements in this area can only choose to introduce new systems. This article by the process of research and improvement to reduce response time. The following service process design and improvement and evaluation.

The original process used by the enterprise is shown in Figure 4 below:

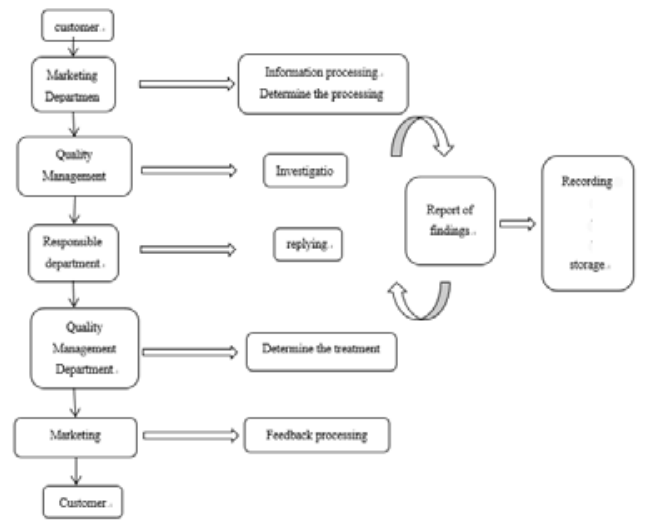


Figure 4: Current process.

As can be seen from the figure, the process is relatively simple. There is only one general process and involved departments. The department has a strong boundary. After-sale service often involves more aspects. One or several departments is difficult to give a sound solution. After-sale service issues require several departments to discuss together to give a win-win decision. In addition, the company's response time is not clearly defined, it is not conducive to quicker, positive problems will be solved. For the above problems on the sale of service processes to improve and the following Figure 5 shows the process.
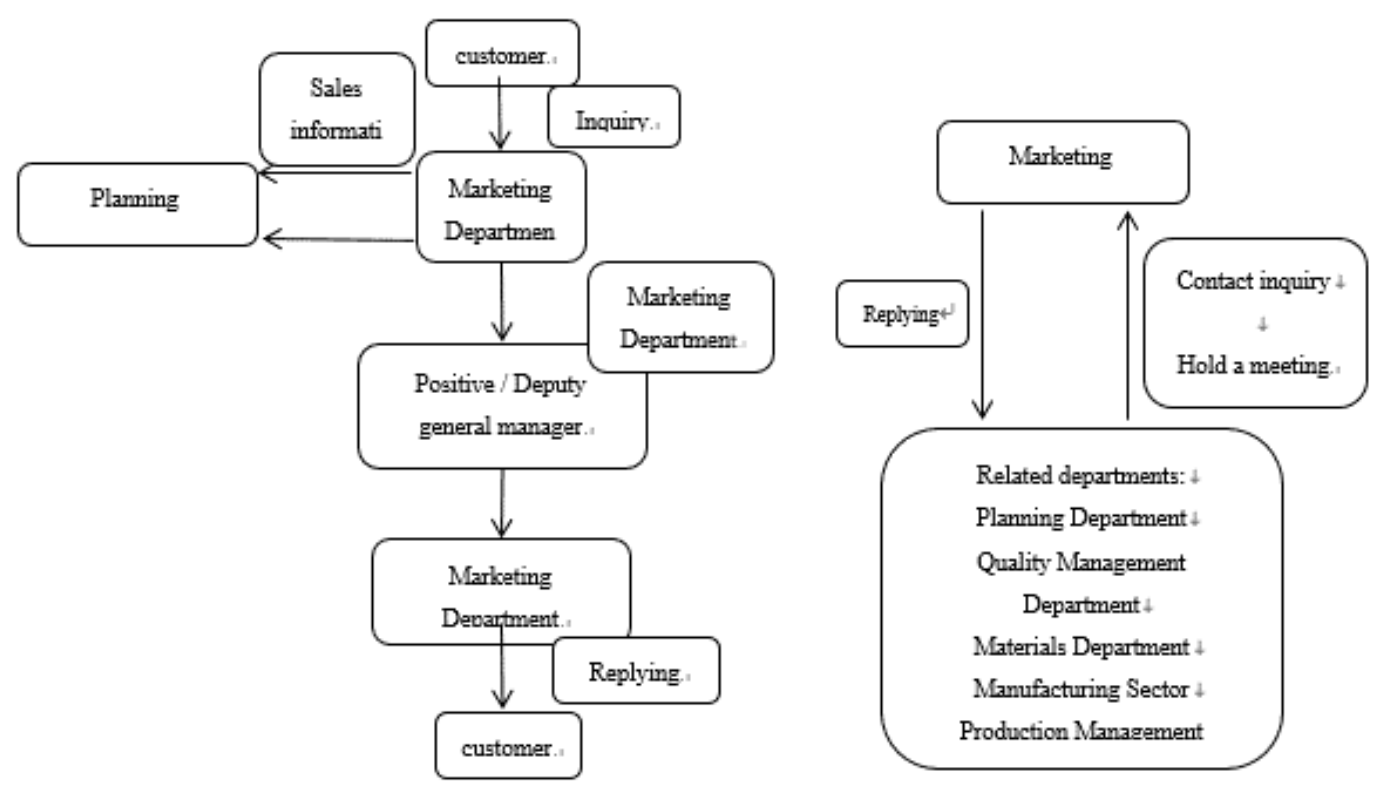

Figure 5: Improved process.

Figure 5 for the design of an improved flow chart, the sale will be reflected in the question to the specialized marketing department of the competent department, the competent department through the customer, the relevant departments to contact and hold meetings to determine the solution to the problem, and ultimately by the marketing department to feedback customer. After the problem is solved, the relevant documents involved shall be kept in custody. The improved process reduces the waiting time for feedback in the intermediate process and discusses and resolves the problems together, avoiding the unity of solution goals and finally solving the win-win problem of both parties.

\section{OPTIMIZED EFFECT VERIFICATION AND PROJECT CONTROL}

\subsection{Validation and Evaluation of Results}

Table 3: Evaluation result

\begin{tabular}{|c|c|c|}
\hline $\begin{array}{c}\text { Processing } \\
\text { system }\end{array}$ & Process & Hours \\
\hline Current & $\mathrm{A}$ & 14.72 \\
\hline Current & $\mathrm{A}$ & 14.64 \\
\hline Current & $\mathrm{A}$ & 13.89 \\
\hline Current & $\mathrm{B}$ & 13.81 \\
\hline Current & $\mathrm{B}$ & 13.78 \\
\hline Current & $\mathrm{B}$ & 13.89 \\
\hline Improve & $\mathrm{A}$ & 12.52 \\
\hline Improve & $\mathrm{A}$ & 12.57 \\
\hline Improve & $\mathrm{A}$ & 14.06 \\
\hline Improve & $\mathrm{B}$ & 9.62 \\
\hline Improve & $\mathrm{B}$ & 7.97 \\
\hline
\end{tabular}

\begin{tabular}{|c|c|c|}
\hline Improve & B & 9.41 \\
\hline
\end{tabular}

The evaluation of the program needs to compare and analyse the data of the pre-improvement system with the improved data, so as to finally obtain the result of whether the improvement is effective. In order to verify the effectiveness of the measures, experts can determine the time to deal with the problems if they cannot be implemented. Three evaluations of the four cases were carried out separately, and the time taken to deal with the problem was estimated and the results shown in Table 3 were obtained.

As can be seen from the final results in Table 6, there are two variables for the process, namely the processing system and the process. The processing system includes the currently used system and the improved system after introduction. The process includes two processes of A and B. A process represents the current process, and B represents the improved process. Hours represent the process completion time. The following control variables, the data are collated, analysed, and then through the completion of the calculation of the time under which circumstances can make the problem the shortest processing time.

First controlling the process, when the whole process A, the data processing. The processing system also includes two factors, which are the current system and the improved system, and the data are summarized and summarized as shown in Table 4 below.

Table 4: Time processing table using process A

\begin{tabular}{|c|c|c|}
\hline $\begin{array}{c}\text { Measurement } \\
\text { number }\end{array}$ & Current system & $\begin{array}{c}\text { Improved } \\
\text { system }\end{array}$ \\
\hline 1 & 14.72 & 12.52 \\
\hline
\end{tabular}




\begin{tabular}{|c|c|c|}
\hline 2 & 14.64 & 12.57 \\
\hline 3 & 13.89 & 14.06 \\
\hline Average value & 14.42 & 13.05 \\
\hline
\end{tabular}

We set the process as the process $B$ to count the current system and the improved system. The results are shown in Table 5 below.

Table 5: Time processing table using process B

\begin{tabular}{|c|c|c|}
\hline $\begin{array}{c}\text { Measurement } \\
\text { number }\end{array}$ & Current system & $\begin{array}{c}\text { Improved } \\
\text { system }\end{array}$ \\
\hline 1 & 13.81 & 9.62 \\
\hline 2 & 13.78 & 7.97 \\
\hline 3 & 13.89 & 9.41 \\
\hline Average value & 13.83 & 9 \\
\hline
\end{tabular}

It can be seen from the above two tables that implementing the improvement system has a much shorter response time than the current system under the same process flow. Therefore, changing the processing system helps to improve the after-sales service time.

Control of the implementation of the system, first in the case of the current system, the process A, B of the time statistics and calculations. The statistical results are shown in Table 6 below.

Table 6: The current system case time processing table

\begin{tabular}{|c|c|c|}
\hline $\begin{array}{c}\text { Measurement } \\
\text { number }\end{array}$ & Process A & Process B \\
\hline 1 & 14.72 & 13.81 \\
\hline 2 & 14.64 & 13.78 \\
\hline 3 & 13.89 & 13.89 \\
\hline Average value & 14.42 & 13.83 \\
\hline
\end{tabular}

The system is set to improved system, respectively, the process A, B statistics, calculations, the results shown in Table 7 below.

Table 7: The current system case time processing table

\begin{tabular}{|c|c|c|}
\hline $\begin{array}{c}\text { Measurement } \\
\text { number }\end{array}$ & Process A & Process B \\
\hline 1 & 12.52 & 9.62 \\
\hline 2 & 12.57 & 7.97 \\
\hline 3 & 14.06 & 9.41 \\
\hline Average value & 13.05 & 9 \\
\hline
\end{tabular}

It can be seen from the above two tables that Process $B$ has a significant effect on the reduction of after-sales service time, indicating that the process of improving after-sales service is effective to improve the response time of after-sale problems. In summary, for customers who are more dissatisfied with the issue of after-sales processing time, you can improve from two aspects, after-sales service system and after-sales service processes. Through the improvement of the above two aspects and the actual measurement of the time spent in the service process, it proves that the improvement from these two aspects is effective.

\subsection{Company's Control Phase}

The control phase is the last stage of the DMAIC process, its main role is to make the target has been set and the relevant standards, processes can be well applied. The control phase needs to confirm and monitor the measures that have played a role, clearly define the key control points and timely update the relevant control plans and related documents.

According to the front of the after-sales service process definition, measurement, analysis and improvement of the various stages of analysis, we determine the customer service needs of the service, the sale of the problem and the root cause of the problem in-depth mining. Finally, we improve the fundamental problems and verify the improvement effect. The control phase needs to grasp the specific problems analysed by the above process and the solutions to the problems. Adhere to the implementation of improvement measures, while we identify problems and effectively solve the problems.

\section{CONCLUSIONS}

This article through the $\mathrm{C}$ company after-sales service process to understand, investigate, analyse, and ultimately affect the customer satisfaction of the most critical aspects of after-sales service hours. Then from the aspect of influencing after-sales service time, two key influencing factors are obtained and two influencing factors are improved. After the improvement of the actual running time through the investigation, we ultimately get improved and improved before the data. Through the analysis of the data, the optimization basically meets the goal set by the project. Through analysing different aspects, it draws two aspects that enterprises should focus on for key problems. In order to constantly maintain the old customers and attract new customers, companies need to constantly investigate these two aspects and found that problems in a timely manner to update the process and systems involved in order to get better business development.

\section{REFERENCES}

[1] Chunyan, Li, 2005. Six Sigma management and customer satisfaction, China Statistics. (1), pp.51-52.

[2] Changming, Dong., QiSheng, Gao., 2014. Research on the improvement of commercial bank service quality based on DMAIC, Exploration of financial theory. (1), pp.36-39.

[3] Li S H, Wu C C, 2011. Improving the efficiency of IT help-desk service by Six Sigma management methodology (DMAIC) - a case study of C company, Production Planning \& Control. 22(7), pp.612-627.

[4] Sushovan, Ghosh., J, Maiti., 2014. Data mining driven DMAIC framework for improving foundry quality - a case study, Production Planning \& Control. 25(6), pp. 478-493.

[5] Xueyang, Yin, Application of DMAIC model in after-sale service management of automobile $4 \mathrm{~S}$ station, Mechanics. 37(12), pp.37-40. 